G438(P) TRANSITION FROM PAEDIATRIC NEURODISABILITY TO ADULT SERVICES; A PATIENT CENTRED APPROACH

${ }^{1} \mathrm{~A}$ Chryssanthakis, ${ }^{1} \mathrm{~B}$ Wilkes, ${ }^{1} \mathrm{I}$ Hadjikoumi, ${ }^{2} \mathrm{C}$ Dalton, ${ }^{2} \mathrm{~V}$ Thakur, ${ }^{1} \mathrm{M}$ McGowan. ${ }^{1}$ Paediatric Neurodisability, St George's Hospital, London, UK; ${ }^{2}$ Neurorehabilitation and Neurology, St George's Hospital, London, UK

10.1136/archdischild-2018-rcpch.427

The transition from paediatric to adult neurodisability services can be a challenging time for young people and their families. This vulnerable group have complex needs encompassing healthcare, social care and education sectors. A new transition clinic for young people with complex neurodisability was established in 2015. Our aim was to ensure a patient-centred approach in developing and improving the current transition service in accordance with NICE guidelines on transition (2016) and cerebral palsy (2017).

The patient cohort was derived from young people referred from the paediatric neurodisability service to the transition 'spasticity' clinic since its establishment in 2015. We used a two pronged apporach in the form of audit and telephone interviews. The audit criteria were derived from NICE guidelines and involved reviewing patients' notes and clinic letters. The structured telephone interviews with patients and parents enabled us to get qualitative feedback on the existing service.

Our cohort of 8 patients were transitioned from paediatric to adult services at a mean age of 17.2 years. As well as the adult neurologist, a paediatrician was present in the transition clinic in 7 of 8 cases. An adult physiotherapist was present in 6 , but a paediatric physiotherapist was only present in 2 . Strengths demonstrated during the clinic included discussing communication and learning needs (7 out of 8 ). Weaknesses included discussing emotional health and planning future involvement of parents/carers. Communication with GPs was present in 5 out of 8 (formal transition letter with GP CC'd). 6 families gave us qualitative feedback.

Based on our results and responses, we co-produced a leaflet with young people and their families on what to expect from the transition process including information about the transition clinic and possible discussion topics, practical information such as new contact details and where to seek emergency care. We also produced a matching 'Patient Passport' to be used as a checklist in the transition clinic to ensure that all aspects of care are covered in the discussion. We hope these interventions will encourage autonomy and informed decision making in the transition process.

\section{G439(P) WELLCOME HOME - THE WORK OF SHELTER, A CHARITABLE ORGANISATION IN FACILITATING THE DISCHARGE OF CHILDREN WITH MEDICAL COMPLEXITIES (CMIC)}

${ }^{1} \mathrm{E}$ Bassett, ${ }^{1} \mathrm{R}$ Shanahan, ${ }^{1,2} \mathrm{~N}$ Allen. ${ }^{1}$ Department of General Paediatrics, Birmingham Children's Hospital, Birmingham, UK; ${ }^{2}$ Birmingham Childrens Hospital Team, Shelter, Birmingham, UK

\subsection{6/archdischild-2018-rcpch.428}

Aims Our CMiC Team coordinate compassionate care and facilitate a safe discharge for patients with complex medical conditions \pm social needs $(\mathrm{CMiC}$ criteria), whilst linking together patient-focused working for health and social care services. WELLcome Home aimed to improve the quality of the long journey home.

Methods Shelter established a pilot 7 month housing support service (WELLcome Home) for CMiC families. An onsite Shelter support worker guides families through the social housing pathway, raises the profile where housing prevents discharge, and contributes to $\mathrm{CMiC}$ multidisciplinary team meetings, bridging the gap between Health and Social Care.

\begin{tabular}{lllllll} 
Abstract G439(P) Table 1 & & & \\
\hline & \multicolumn{1}{l}{$\begin{array}{l}\text { Score before WELLcome } \\
\text { home }\end{array}$} & \multicolumn{3}{l}{$\begin{array}{l}\text { Score after WELcome } \\
\text { home }\end{array}$} \\
\hline & $1-4$ & $5-8$ & $>8$ & $1-4$ & $5-8$ & $>8$ \\
\hline Emotional and Mental wellbeing & $47 \%$ & & & & $58 \%$ & \\
Managing at home & $47 \%$ & $29 \%$ & & & $75 \%$ & $25 \%$ \\
Managing tenancy & $24 \%$ & $41 \%$ & $18 \%$ & & $58 \%$ & $42 \%$ \\
Financial worries & $12 \%$ & $41 \%$ & $18 \%$ & $17 \%$ & $58 \%$ & $25 \%$ \\
Physical health & $18 \%$ & $65 \%$ & $18 \%$ & $8 \%$ & $67 \%$ & $25 \%$ \\
Social networks and relationships & $24 \%$ & $59 \%$ & $6 \%$ & $8 \%$ & $62 \%$ & $8 \%$ \\
Confidence & $29 \%$ & $59 \%$ & & & $83 \%$ & $17 \%$ \\
\hline (1 poor, 10 excellent) & & & & & &
\end{tabular}

Results Service-user evaluation questionnaires provided qualitative data across seven modalities (table 1).

Conclusion The WELLcome home project demonstrated positive qualitative outcomes across all modalities assessed. Between January-June 2017, housing provided discharge barriers for 15 long-stay patients. Additional length of stay due to housing need exceeds 1000 bed-days for this patient subgroup. Funding for Shelter at our Hospital is secured for 5 years. Collaborative, imaginative working is vital to continue supporting our most vulnerable and complex families.

\section{British Society for the History of Paediatrics and Child Health}

\section{G440 CHILDHOOD HEALTH PROMOTION DURING 1870-1901}

EJ Estlin. Department of Child Health, Blackpool Teaching Hospitals NHS Foundation Trust, Blackpool, UK

\subsection{6/archdischild-2018-rcpch.429}

Aim Taking physical education as an exemplar, the aim of this study is to explore and discuss child health promotion in Britain and the USA during the late Victorian era (LVA), utilising the Children and Youth version of the WHO International Classification of Functioning, Disability and Health (ICF-CY) as a frame for analysis. The ICF-CY describes the interrelationships of body structures and function; of activities and participations and of the contextual influences of environment and personal factors for given health states.

Methods Archival papers were identified from searches of PubMed; the LA84 Foundation and the library search functions of the Manchester Metropolitan University and subject to Framework Analysis as supported by the ICF-CY.

Results The literature of the LVA saw an emphasis on the physical education of boys. In terms of body structures and functions, advances in the physiology of diet and exercise, 